\title{
Roles of glucose transporter-1 and the phosphatidylinositol 3-kinase/protein kinase B pathway in cancer radioresistance (Review)
}

\author{
JIN FANG $^{1,2}$, SHUI-HONG ZHOU ${ }^{2}$, JUN FAN $^{3}$ and SEN-XIANG YAN ${ }^{4}$ \\ ${ }^{1}$ Department of Otolaryngology, The Second Hospital of Jiaxing City, Jiaxing, Zhejiang 314000; \\ ${ }^{2}$ Department of Otolaryngology; ${ }^{3}$ State Key Laboratory for Diagnosis and Treatment of Infectious Diseases; \\ ${ }^{4}$ Department of Radiotherapy, The First Affiliated Hospital, College of Medicine, \\ Zhejiang University, Hangzhou, Zhejiang 310003, P.R. China
}

Received January 28, 2014; Accepted September 19, 2014

DOI: $10.3892 / \mathrm{mmr} .2014 .2888$

\begin{abstract}
The mechanisms underlying cancer radioresistance remain unclear. Several studies have found that increased glucose transporter-1 (GLUT-1) expression is associated with radioresistance. Recently, the phosphatidylinositol 3-kinase (PI3K)/protein kinase B (Akt) pathway was reported to be involved in the control of GLUT-1 trafficking and activity. Activation of the PI3K/Akt pathway may itself be associated with cancer radioresistance. Thus, increasing attention has been devoted to the effects of modifying the expression of GLUT-1 and the PI3K/Akt pathway on the increase in the radiosensitivity of cancer cells. This review discusses the importance of the association between elevated expression of GLUT-1 and activation of the PI3K/Akt pathway in the development of radioresistance in cancer.
\end{abstract}

\section{Contents}

1. Introduction

2. Overexpression of GLUT-1 and radioresistance

3. Role of PI3K/Akt in radioresistance

4. Association between GLUT-1 and PI3K/Akt

5. Conclusion

Correspondence to: Professor Shui-Hong Zhou, Department of Otolaryngology, The First Affiliated Hospital, College of Medicine, Zhejiang University, 79 Qingchun Road, Hangzhou, Zhejiang 310003, P.R. China

E-mail: zhouyunzhoush@163.com

Key words: phosphatidylinositol 3-kinase/protein kinase B pathway, glucose transporter-1, cancer, radioresistance

\section{Introduction}

Glucose is one of the primary energy sources required to maintain the normal functioning of cells. The glucose transporters (GLUTs) mediate glucose transport (1). Compared with their nonmalignant counterparts, the metabolic rate of glucose is higher in malignant cells. This phenomenon has been demonstrated using positron emission tomography (PET) scanning with the glucose analog tracer, ${ }^{18} \mathrm{~F}$-2-fluoro-2-deoxy-D-glucose $\left({ }^{18} \mathrm{~F}-\mathrm{FDG}\right)(2-4)$. Several mechanisms of ${ }^{18} \mathrm{~F}-\mathrm{FDG}$ uptake that may explain the accelerated glucose use in growing tumors and in transformed and malignant cells have been proposed, including passive diffusion, $\mathrm{Na}^{+}$-dependent glucose transport, the activation of oncogenes, the phosphatidylinositol 3-kinase/protein kinase B (PI3K/Akt) pathway and upregulation of facilitative GLUT (5-8). GLUT5 is considered to be the primary mechanism for increasing glucose influx into cells (5).

GLUTs are membrane proteins that facilitate the transport of glucose across cellular membranes. Thirteen members of the facilitative sugar transporter family are now recognized (GLUT-1 to -12 and HMIT; gene name, SLC2A) (9). The human genes encoding these proteins are named GLUT-1 to -5 and GLUT-7 to -13 ; GLUT-6 and -14 are now known to be pseudogenes. Of the 14 isoforms, GLUT-1 appears to be the most ubiquitously distributed (10). A number of studies have shown increased GLUT-1 expression in various types of cancer (11-16), including in head and neck cancer (5,17-20). It has been reported that overexpression of GLUT-1 is associated with lymph node metastasis and a poor prognosis in head and neck cancers (17-20). Thus, GLUT-1 may be a potential therapeutic target in malignant tumors $(14,16,21-24)$.

Radiotherapy is important in treating advanced cancers and in organ preservation strategies for cancers at an earlier stage (25). However, radioresistance of cancer cells affects treatment efficacy.

To date, a number of strategies have been introduced in an attempt to increase radiosensitivity, including hyperfractionation to overcome intrinsic radioresistance (26-28), concurrent chemoradiotherapy $(29,30)$ and the use of certain radiosensitizers that enhance radiosensitivity by improving the hypoxic 
status of tumors $(31,32)$. Although these efforts have increased survival rates and regional control, certain issues have been reported and the effects are less than ideal, including the development of central radionecrosis as well as early or late toxicity. Thus, more efficacious treatments with fewer side effects are required in order to improve radiosensitivity.

Although a number of factors contributing to radioresistance are understood, such as hypoxia, re-population and DNA damage repair, other aspects remain unclear. A number of studies have found that increased GLUT-1 expression is significantly correlated with radioresistance (33-38). Thus, the suppression of GLUT-1 expression as a novel therapeutic target is a focus in research into increasing radiosensitvity of malignant tumors $(33,34,39)$. However, abnormal expression of GLUT-1 in malignant tumors is not the only cause of radioresistance. Other genes, including epidermal growth factor receptor (EGFR) and NOTCH, may also be involved $(40,41)$. Abnormal expression of GLUT-1 and its activity are regulated by a number of factors, including the activation of oncogenes $(13,42)$, hypoxia via hypoxia-inducible factor (HIF)-1-dependent and independent mechanisms $(42,43)$, and signaling pathways, such as mitogen-activated protein kinase (MAPK) (44), and the PI3K/Akt pathway (45-47). Recently, the PI3K/Akt pathway was reported to be involved in the control of GLUT-1 trafficking and activity $(1,48,49)$. It was also suggested that the PI3K/Akt pathway may regulate GLUT-1 localization in T cells $(1,47)$.

The PI3K/Akt pathway is often found to be overactive in a variety of tumor types and triggers a cascade of responses, from cell growth and proliferation to increased cell survival and motility, which drive tumor progression (40). Activation of the PI3K/Akt pathway may be associated with radioresistance of cancer $(25,50-52)$. Thus, research has become increasingly focused on modifying the expression of GLUT-1 and the PI3K/Akt pathway in order to increase radiosensitivity.

Although GLUT-1 expression is a common feature in patients with cancer, the prognostic value of this parameter, along with the degree of FDG uptake, has not been evaluated with respect to PI3K/Akt. The selection of GLUT-1 and Akt as targets is logical considering their importance in cancer survival and resistance to radiation and chemotherapy.

This review discusses the role of an interaction between the elevated expression of GLUT-1 and activation of the PI3K/Akt pathway in cancer radioresistance. It is proposed that suppression of GLUT-1 expression and the PI3K/Akt pathway may be therapeutic targets for carcinomas (Fig. 1).

\section{Overexpression of GLUT-1 and radioresistance}

A number of studies have demonstrated that increased GLUT-1 expression is associated with the development of radioresistance in cancer. In the CPH 54A and CPH 54B lung cancer cell lines, $\mathrm{CPH} 54 \mathrm{~A}$ tumors are more radiosensitive than $\mathrm{CPH} 54 \mathrm{~B}$ tumors in vivo and in vitro. Pedersen et al (36) found that GLUT-1 mRNA and protein expression levels are higher in 54B than in 54A cells. They also detected greater FDG uptake in 54B tumors, using PET scans, and suggested that there appears to be a correlation between the level of GLUT-1 and FDG uptake. Brophy et al (53) investigated GLUT-1 expression in 69 pretreatment biopsy samples from

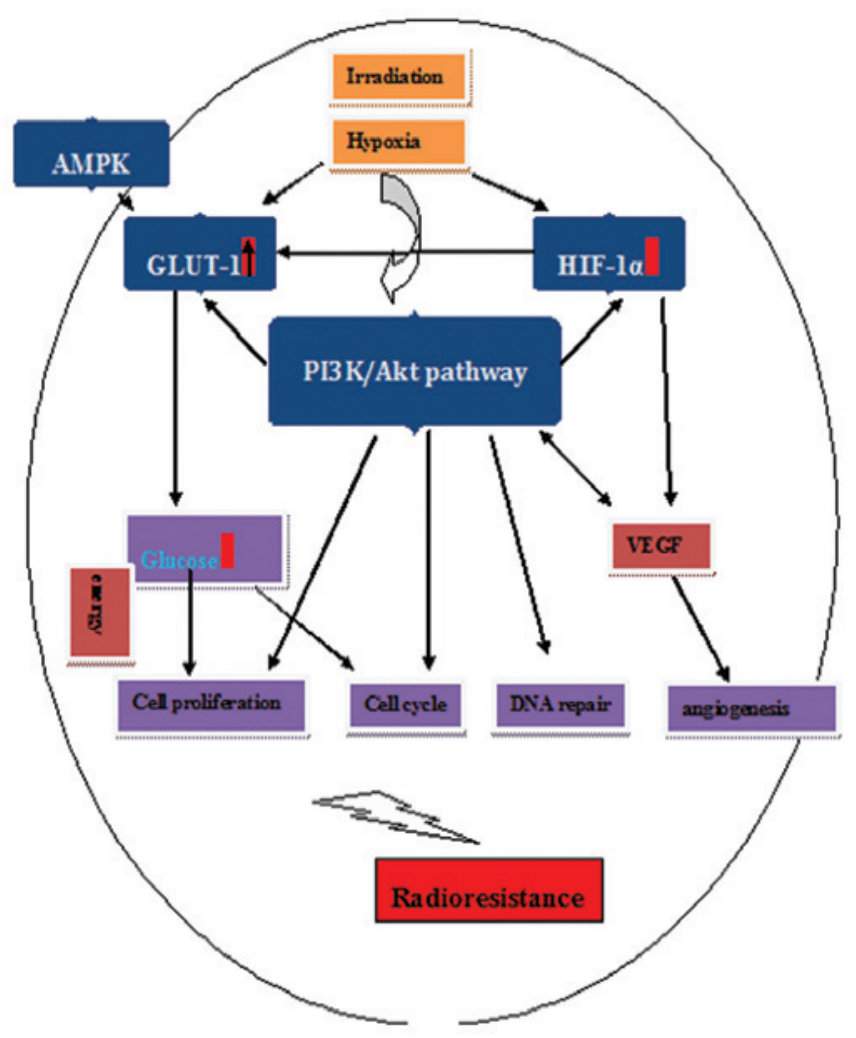

Figure 1. Role of GLUT-1 and PI3K/Akt in radioresistance. GLUT-1, glucose transporter 1; HIF-1 $\alpha$, hypoxia-inducible factor-1 $\alpha$; AMPK, AMP-activated protein kinase- $\alpha$; VEGF, vascular endothelial growth factor.

patients with rectal cancer. The patients received preoperative chemoradiotherapy followed by surgical resection. GLUT-1 negative tumors had a 70\% probability of a good response to chemoradiotherapy compared with a response rate of $31 \%$ for GLUT-1 positive tumors. Korkeila et al (37) compared the expression of GLUT-1 in 53 operative samples from patients who had undergone a surgical resection for rectal cancer and 78 preoperative biopsies of patients with rectal cancer who had been treated by preoperative radiotherapy. They found that negative or weak GLUT-1 expression was linked to pronounced tumor regression. There was a tendency towards improved disease-free survival following a long course of radiotherapy when GLUT-1 staining intensity in the operative sample was negative or weak (37). Another study found that preoperative radiotherapy markedly upregulated the expression of GLUT-1 (31). Saigusa et al (33) investigated whether GLUT-1 expression was associated with clinical outcome in 52 patients with rectal cancer following preoperative chemoradiotherapy. They found that elevated GLUT-1 gene expression was associated with a more advanced stage of the disease, lymph node metastasis and distant metastasis, and was an independent predictive factor for recurrence-free and overall survival. In vitro, DLD1 and LoVo colorectal cancer cell lines show high expression of GLUT-1 whereas the Caco-2 colorectal cancer cells have a lower level of expression of GLUT-1 (33). The relative gene expression levels of GLUT1 in DLD1 and LoVo cells were found to be 30- and 14-fold that of Caco-2, respectively. It was observed that DLD1 cells, which had the highest GLUT-1 gene expression levels, were more resistant to irradiation than Caco-2 and LoVo cells. However, 
LoVo cells were more sensitive to radiation than Caco- 2 cells One possible explanation for this may be that radiosensitivity is dependent on Ki-67 expression, as LoVo cells exhibited the highest MKI67 gene expression of the seven cell lines examined. Following chemoradiotherapy, residual cancer growths may contain cells with different characteristics, depending on their location. GLUT-1 expression is predominantly found in the central portion of such residual cancer masses (33). Finally, it was observed that the growth of DLD1 and LoVo cells was inhibited by the glycolysis inhibitor 3-BrPA to a greater extent than that of Caco- 2 cells. This suggested that the inhibition of glycolysis may be a potential novel strategy for the treatment of patients with colorectal cancer who express the KRAS mutation (33).

Few studies have investigated the association between GLUT-1 and radioresistance in cancer (19,35). A GLUT-1 labeling index (LI) was determined using immunohistochemistry in 40 biopsies from patients with oral squamous cell carcinoma (OSCC) prior to treatment (19). Clinical responders to radiation showed a significantly lower expression of GLUT-1 when compared with incomplete responders $(\mathrm{P}=0.009)$. A significant association $(\mathrm{P}=0.023)$ was observed between the GLUT-1 LI and the resistance of tumor cells. These results suggest that GLUT-1 expression could be considered to be a marker of radioresistance in OSCC, in which high GLUT-1 expression is associated with a poor radiation response and vice versa (19). Doki et al (35) found a high level of expression of GLUT-1 in squamous cell carcinoma of the esophagus following radiotherapy. In a previous study, it was shown that GLUT-1 overexpression in vitro is associated with increased cell proliferation and glucose uptake in Hep-2 laryngeal carcinoma cells. Conversely, the suppression of GLUT-1 expression by antisense oligodeoxynucleotides (AS-ODNs) may decrease glucose uptake and inhibit the proliferation of Hep-2 cells (54). Recently, it was shown that radioresistance in laryngeal carcinoma cells may be associated with increased expression of GLUT-1 mRNA and protein. GLUT-1 AS-ODNs may enhance the radiosensitivity of laryngeal carcinoma cells, primarily by inhibiting the expression of GLUT-1 in vitro and in vivo (55).

\section{Possible mechanisms of GLUT-1-mediated radioresistance} Raised glucose metabolic rate. A higher glucose metabolic rate has been observed in malignant tumor cells compared with non-malignant cells, even during aerobic glycolysis. This phenomenon is referred to as the Warburg effect $(56,57)$ and was demonstrated using PET scanning with the glucose analog tracer FDG (58). Transport of glucose across the plasma membrane is the initial rate-limiting step in glucose metabolism and it is mediated by facilitative glucose transporter proteins (59). GLUT-1 is important in glucose metabolism within malignant cells and may contribute to the observed increase in FDG uptake. In addition, GLUT-1 may be an intrinsic marker of hypoxia in malignant tumors (14,16,21-24). Elevated GLUT-1 expression may enable malignant tumors to increase their energy expenditure leading to proliferation and radioresistance of tumor cells.

Hypoxia. Hypoxic cells represent $10-50 \%$ of solid tumor cells. Hypoxia is known to promote chemoradioresistance in carcinomas $(60,61)$. In addition, GLUT-1 is overexpressed in hypoxic states. HIF-1 $\alpha$, a transcription factor associated with the cellular response to hypoxia (62), upregulates the expression of several hypoxia response genes, including GLUT-1 (64). A correlation has been demonstrated between GLUT-1 and HIF-1 $\alpha$ expression in laryngeal carcinoma (65). It is suggested that GLUT-1 expression is associated with cancer radioresistance as a result of upregulation by HIF-1 $\alpha$.

GLUT-1 expression increases cell metabolism. Evans et al (66) showed that GLUT-1 overexpression without a coordinated increase in HIF-1-regulated glycolytic enzymes increased glucose uptake but not the glycolytic rate (66). They found that increased GLUT-1 expression resulted in chemoresistance by increasing cell turnover. Thus, it is possible that a similar mechanism may be involved in GLUT-1-mediated radioresistance. However, this requires further investigation.

Involvement of cancer stem cells. CD133+ cancer stem cells may be important in the development of cancer radioresistance $(67,68)$. Ke et al $(67)$ reported that GLUT-1 expression was higher in $\mathrm{CD}_{133^{+}}$than $\mathrm{CD} 133^{-}$cells in thyroid cancer following ${ }^{131}$ I radiotherapy. Mai et al (69) showed that stem cells from proliferating hemangiomas may produce GLUT-1. In a previous study, our group found higher GLUT-1 mRNA and protein expression in CD133 ${ }^{+}$Hep-2 laryngeal carcinoma cells than in $\mathrm{CD}^{-} 3^{-}$cells (70). This also requires further investigation.

Mechanisms independent of hypoxia. A number of studies have shown that GLUT-1-mediated chemoradioresistance is independent of hypoxia. Mayer et al (44) found no correlation between the expression of GLUT-1 and oxygenation variables. Evans et al (66) showed that GLUT-1 overexpression was coordinated with increases in HIF-1-regulated glycolytic enzymes, which increased glucose uptake, but not the rate of glycolysis. GLUT-1 overexpression was correlated with higher levels of phosphodiesterase in xenografts, which was related to the metabolic turnover of phospholipids and involved in membrane lipid degradation, indicating a mechanism by which GLUT-1 may be involved in increased cell turnover (66). The regulation of GLUT-1 expression is dependent not only on HIF-1-induced transcription but also on the post-transcriptional steady-state of the GLUT-1 gene (71).

Changes in the cell cycle and apoptosis. The cell cycle may be involved in cancer radioresistance (72-74). $\mathrm{G}_{2} / \mathrm{M}$ phase arrest occurs in a significant number of cancer cells following irradiation. A previous study found that the percentage of cells that were arrested in the $\mathrm{G}_{2} / \mathrm{M}$ phase increased in a dose-dependent manner in response to radiation. This indicated that entry into mitosis had been delayed by the administration of radiation. $\mathrm{G}_{2} / \mathrm{M}$ arrest in the $12-\mathrm{Gy}$ group was maximal, whilst the expression of GLUT-1 mRNA and protein was higher than that in the control groups (55).

Involvement of signaling pathways. AMPK and PI3K/Akt signaling pathways may regulate the expression of GLUT-1.

\section{Role of PI3K/Akt in radioresistance}

Radiotherapy affects the expression of oncogenes and tumor suppressor genes. This alters internal and external signal transduction pathways of the cells, and affects the response of tumor cells to radiotherapy (24). Since 1995, the PI3K/Akt survival signal transduction pathways have been shown to be involved in regulating the expression of a variety of tumor biology 
markers $(25,53,75)$. PI3K is an important dimer enzyme that is involved in growth and proliferation, and growth factor signal transduction pathways have been found in recent years that may be activated primarily by a combination of growth factors and receptors $(75,76)$. Akt is also termed PKB or Rac. PI3K is one of the important downstream serine-threonine regulation kinases. A variety of molecules may activate Akt, such as insulin, heat shock proteins and tumor necrosis factor- $\alpha$. Activated Akt is central to the mediation of cell growth, survival and differentiation by the PI3K/Akt signal transduction pathways. The biological effects of the activation of this pathway include apoptosis, cell cycle regulation and promotion of invasion, metastasis and angiogenesis $(75,76)$. The abnormal expression of certain proteins, as well as abnormal increases in kinase activity in the Akt cascade signal pathway have been identified in a number of human malignancies. The PI3K/Akt pathway is associated with the increased proliferation of tumor cells, and its activation is closely correlated with a poor prognosis and resistance to cancer radiotherapy.

Possible mechanisms of radiation resistance caused by PI3K/Akt include hypoxia, intrinsic radiation resistance, and external factors, such as tumor cell proliferation following radiation therapy $(25,75)$.

PI3K/Akt and hypoxia in radiation resistance. The association between PI3K/Akt and the hypoxic microenvironment of tumors is of interest in research into radioresistance. Hypoxia often results in an increase in the glucose metabolic rate of malignant cells. The abnormal expression of GLUT-1 is known to be correlated with these factors. The supply and consumption of oxygen in the majority of solid tumors are not balanced, which results in tumor hypoxia. Cells that are progressing through the cell cycle become hypoxic so that their progression becomes delayed relative to well-oxygenated cells. Slower progression of hypoxic than normoxic cells through $\mathrm{G}_{2}$ leads to a temporary accumulation of hypoxic $\mathrm{G}_{2}$ cells in poorly differentiated mammary adenocarcinoma non-transgenic (NT) and anaplastic sarcoma F. Progression of hypoxic cells through the cell cycle in each tumor type is delayed as a result of the deprivation of oxygen and other nutrients (78). Koritzinsky et al (78) found that when cells that had arrested in $\mathrm{G}_{1}$ during hypoxic conditions progressed through S-phase following re-oxygenation, the speed with which they progressed was similar to that of untreated cells. By contrast, the cells that had arrested in S-phase during hypoxia progressed more slowly through this $\mathrm{S}$-phase following re-oxygenation. Groups of cells that maintain proliferative capacity under hypoxic conditions are a significant cause of treatment failure.

Hypoxia results in genomic instability and increased instability in the malignant phenotype by stimulating invasion and metastasis of tumors (79). Hypoxia induces and promotes the mutation of key regulatory genes (HIF-1, solute carrier family 2 and phosphatidylinositol-dependent kinase-1) (80), leading to increased resistance to therapy.

One of the key genes involved in the response to hypoxia is HIF. HIF regulates the expression of $>60$ genes involved in angiogenesis, anaerobic glycolysis and cell survival, and the coordinated expression of these genes results in cellular adaptation to acute and chronic hypoxia (81). Studies have shown that hypoxia of head and neck squamous cell carcinoma is associated with poor local control and overall survival $(82,83)$. The PI3K/Akt signal pathway is important in promoting an adaptive response to low levels of oxygen in tumor cells.

Radiation increases HIF-1 activity, which has been hypothesized to be involved in regulating the tumor response to irradiation through a number of mechanisms (84). The PI3K/Akt pathway is involved in HIF-1 $\alpha$ protein expression. Activation of PI3K/Akt/mammalian target of rapamycin (mTOR) leads to stimulation of de novo synthesis and transcriptional activation of HIF-1 $\alpha(85,86)$. HIF- $1 \alpha$ protects tumors from radiation damage directly and indirectly. Inhibition of the PI3K/Akt pathway by wortmannin and LY294002, and inhibition of HIF-1 $\alpha$ by short interfering (si)RNA may therefore enhance the efficacy of radiotherapy.

PI3K/Akt, reoxygenation and neoangiogenesis in radiation resistance. Irradiation may lead to reoxygenation and neoangiogenesis of cancer cells following radiotherapy. The regulatory mechanism may occur via upregulation of VEGF. Inhibition of neoangiogenesis results in normalization of the vasculature and improved perfusion, leading to a reduction in tumor cell hypoxia (50). The PI3K/Akt pathway may induce the expression of VEGF via activation of HIF-1 $\alpha$ (87). VEGF protects endothelial cells against radiation by activating the PI3K/Akt pathway, leading to enhanced expression of the antiapoptotic protein Bcl-2 (88). Antiangiogenic therapy may therefore enhance the cytotoxic effects of radiotherapy $(89,90)$. Certain antiangiogenic drugs target the vasculature, directly or indirectly, by disrupting VEGF. These include inhibitors of the PI3K/Akt pathway. This may lead to increased blood flow and oxygenation, thereby potentially increasing radiosensitivity (91). A combination of low doses of a PI3K inhibitor (LY294002) and cisplatin significantly enhanced the therapeutic efficacy of radiation therapy by preferentially targeting tumor blood vessels (89). However, the hypothesis that an inhibitor of the PI3K/Akt pathway may also achieve prolonged vascular normalization, and thereby enhance radiosensitivity, requires further investigation (92).

$P I 3 K / A k t$ and the cell cycle in radiation resistance. Radiation may activate p53-dependent or independent cell cycle $\mathrm{G}_{1}$ and $G_{2}$ arrest (93). The PI3K/Akt pathway acts to overcome p53-independent cell cycle arrest via activation of cyclin D and inactivation of the cell cycle-dependent kinase inhibitor p27 (94). Activation of the Akt/PKB pathway is able to override the $G_{2} / M$ phase cell cycle arrest that occurs as a result of irradiation-induced DNA damage (95). Phosphatase and tensin homolog (PTEN), a tumor-suppressor gene, antagonizes the PI3K/AKT signaling pathway that is involved in promoting escape from cell-cycle arrest. Park et al (94) found that PTEN may be essential in cancer cell radiosensitivity by using LY294002 or PTEN-specific siRNA to block PI3K/Akt signaling in non-small-cell lung cancer cells (NSCLC).

$P I 3 K / A k t$ and DNA repair in radiation resistance. Irradiation may cause DNA damage, including single-strand breaks, double-strand breaks (DSBs), base excision and glucose damage. Enhanced DNA repair activity tends to be resistant to radiotherapy. DNA-dependent protein kinase catalytic subunit 
(DNA-PKcs) and ataxia telangiectasia-mutated are two members of the PI3K family that repair DNA DSBs (97-99). Inhibition of PI3 kinases using a pharmacological approach may improve the response of cancer cells to radiotherapy. Nimotuzumab inhibits the radiation-induced activation of DNA-PKcs by blocking the PI3K/AKT pathway (99). Inhibition of the PI3K/Akt cell survival signaling pathway and DNA-PKcs may contribute to the wortmannin-induced radiosensitivity observed in NSCLC cells (100). Azad et al (101) found that BEZ235, a novel inhibitor of DNA-PK and PI3K/mTOR, abrogates radiation-induced DSB repair, resulting in cellular radiosensitization and growth delay in irradiated NSCLC xenografts.

PI3K/Akt, epidermal growth factor receptor (EGFR) and cell proliferation in radioresistance. Activated Akt promotes cell proliferation and inhibits apoptosis. Radiation-induced Akt activation may modulate the radioresistance of human cancer cells (102). Certain serum factors, including integrin- $\beta 1$, and growth factor receptors, including EGFR, may also be involved (103,104). Minjgee et al (103) showed that there was increased basal Akt phosphorylation as well as augmented output from the PI3K/Akt pathway following EGF stimulation in cell lines with higher levels of ErbB1 and integrin- $\beta 1$ expression. Akt phosphorylation may be related to adhesion and migration, which are regulated by integrin signaling. Inhibition of AKT, EGFR and integrin- $\beta 1$ may thus improve radioresistance (104).

\section{Association between GLUT-1 and PI3K/Akt}

The abnormal expression of GLUT-1 is correlated with multiple signal transduction pathways, including the PI3K/Akt signaling pathway, which is known to be important in the regulation of GLUT-1 expression. Several studies have confirmed that the PI3K/Akt pathway and GLUT-1 expression affect glucose metabolism (1,47-49).

Hematopoietic cells and T lymphocytes depend on GLUT-1 as the primary source of intracellular glucose, while growth factors, such as interleukin (IL)-3, IL-7 or CD28 provide important signals for GLUT-1 synthesis and glucose uptake in these cells (47,105-107). Cell growth factors regulate GLUT-1 predominantly through PI3K and its downstream effector Akt. This leads to activation of mTOR and glycogen synthetase-3 (GSK-3), as well as other methods of controlling the activation, recirculation and internalization of GLUT-1.

In addition to the regulation of GLUT-1 expression at the cell surface, Akt also controls the activity of GLUT-1 via activation of mTOR (106). In hematopoietic cells and T cells that have been transfected with the GLUT-1 gene, an increase in glucose metabolism results in increased levels of phosphorylation of GSK-3 $\alpha, \beta$ (108). It has been reported that Akt phosphorylates 21/9 serine of GSK-3 directly, thus inhibiting the activity of GSK-3 kinase (48). As a substrate of Akt, GSK-3 can also regulate the transmission of GLUT-1 by improving the recycling of integrin (109). Continuous activation of $\mathrm{Akt}$ expression increases the ability of lymphocytes to absorb and utilize glucose $(48,107,110)$, improves the glycolysis of T lymphocytes (107) and may lead to the development of autoimmune disorders and lymphoma. Suppression of PI3K can prevent the activation of lymphocytes, increase glucose metabolism following stimulation by cytokines and reduce the ability of leukemic cells to absorb glucose (1,110-112).

PI3K pathways also affect insulin-induced glucose transport in fatty cells $(113,114)$. Apigenin downregulates the expression of GLUT-1 mRNA and protein in CD18 and S2-013 pancreatic cancer cell lines, and inhibits the PI3K/Akt channel $(49,115)$. It has been found that inhibition of the PI3K/Akt pathway may induce a decrease in GLUT-1 mRNA $(112,116)$.

Research has shown that cell growth factors promote the transmission and activation of GLUT-1 in hematopoietic cells and T lymphocytes via the PI3K/Akt pathway (48,105-107), and that activated Akt is sufficient to maintain GLUT-1 and glucose uptake on the surface of cells in the absence of cytokines $(107,117)$. A previous study found that expression of GLUT-1, p-Akt, and PI3K protein in adenoid cystic carcinoma (ACC) was higher than that in inflammatory lesions or benign tumors $(\mathrm{P}<0.001)$. The percentage of cells expressing these proteins for GLUT-1, PI3K and p-Akt protein in ACC were 38.1 (16/42), 38.1 (16/42) and 50.0\% (21/42), respectively. Significant correlations between GLUT-1 and PI3K expression $(r=0.394$, $\mathrm{p}=0.01)$, between GLUT-1 and $\mathrm{p}-\mathrm{Akt}$ expression $(\mathrm{r}=0.528$, $\mathrm{P}<0.001)$, and between $\mathrm{p}-\mathrm{Akt}$ and PI3K expression $(\mathrm{r}=0.528$, $\mathrm{P}<0.001)$ were also observed. In this study, a multivariate analysis showed that p-Akt was a significant predictor of recurrence and that GLUT-1 expression was associated with T stage (according to the TNM classification) and distant metastasis of ACC (118). In a ceruminous adenoma of the external auditory canal, it was also shown by immunohistochemistry that tumor cells were positive for GLUT-1, HIF-1, PI3K and p-Akt (119). In U87MG glioblastoma cells, inhibition of the PI3K pathway by LY294002 may decrease the expression of GLUT-1 mRNA, VEGF mRNA, and HIF-1 $\alpha$ mRNA (116).

mTOR is a downstream target of PI3K. Radhakrishnan et al (112) found that GLUT-1 was linked to the mTOR pathway and that GLUT-1 may be useful as a biomarker of mTOR status in head and neck cancers. mTOR inhibition may activate an AKT feedback loop in tumors sensitive to rapamycin treatment. In acute lymphoblastic leukemia, IL-17 upregulates the expression of GLUT-1 via PI3K activation $(120,121)$. In endometrial carcinoma cells, GLUT-1, pAkt and pmTOR were found to be strongly expressed and the mTOR inhibitor, rapamycin, induced apoptotic cell death (122). However, in breast cancer cells, rapamycin and sorafenib downregulated GLUT-1 expression and glucose uptake to similar extents, whereas the dual PI3K/mTORC1-C2 inhibitor NVP-BEZ-235 did not have the same effect. This suggested that sorafenib-mediated activation of AMPK, rather than the PI3K/Akt pathway, initially stimulated glucose uptake by increasing GLUT-1 protein expression (123).

It is a novel idea to target GLUT-1 and AKT expression with the aim of improving the radiosensitivity of cancers. Other signaling pathways are involved in cancer radioresistance, not all of which regulate or interact with GLUT-1, and which may indeed be independent of the glucose/AKT pathway. The stress-activated protein kinase/c-Jun NH(2)-terminal kinase pathway has been found to be involved in the radioresistance of nasopharyngeal carcinoma (124). The RAF kinase/mitogen activated protein kinase/extracellular signal-regulated kinase (ERK) pathways are also important in the radiation resistance of squamous cell cancers, and kinase suppressor of RAS 1 
AS-ODN may act a radiosensitizer for treating Ras-dependent human malignancies (125). It has been observed in clinical trials that inhibition of PI3K (126) and GLUT-1 (127) increase the expression of other oncogenes, such as that of pERK1/2 or pEGFR, and induce the persistent phosphorylation of ribosomal protein S6. ERK1/2 activates the p90 ribosomal S6 kinase (128), which subsequently phosphorylates S6 at Ser235/236, independently of PI3K/mTOR signaling, and increases tumor resistance to radiation therapy (129).

\section{Conclusion}

Activation of the PI3K/Akt pathway, and the transcription and expression of GLUT-1 (promoted by PI3K/Akt) are closely associated with glucose uptake, energy consumption, cell proliferation and the malignant transformation of tumor cells. GLUT-1 activation by PI3K/Akt is an important metabolic regulator of tumor cells. Overexpression of molecules in this pathway is associated with a poor prognosis and resistance to radiotherapy.

Radiation resistance of tumor cells, which develops during the course of radiotherapy, necessitates the development of novel therapies to combat this problem. The radiosensitivity of tumor cells is key to treatment efficacy and is associated with their inherent sensitivity prior to irradiation as well as adaptations developed to deal with injury following irradiation. Intrinsic radiosensitivity is determined genetically and by disorders involving tumor suppressor genes, while the response of cells to injury is induced by protein modifications and ultimately by relevant alterations in signal transduction pathways.

Preclinical data have shown that enhancing radiosensitivity by inhibiting PI3K/Akt is possible. LY294002 and wortmannin, which target the p110 catalytic subunit of PI3K, provide powerful preclinical tools with which to investigate the cellular consequences of inhibiting this pathway $(94,100)$. RAD-001, a rapamycin analog, is a potent radiosensitizer that acts via mTOR-dependent enhancement of radiation-induced autophagy and the induction of apoptosis in vascular endothelial cells $(130,131)$. In a phase III trial, CCI-779, another mTOR inhibitor, showed a significant improvement in progression-free survival (5.5 compared with 3.1 months) and in overall survival in patients with metastatic renal cell carcinoma (132). However, no data on enhancing radiosensitivity by combining inhibition of PI3K/Akt with that of GLUT-1 expression in carcinomas are available to date. A number of studies have shown that activation of the PI3K/Akt signaling pathway and abnormal expression of GLUT-1 are associated with tumor progression, a poor prognosis and the development of resistance to chemotherapy and radiotherapy. The ability of a malignancy to resist radiation-induced damage is associated with PI3K/Akt and the overexpression and activation of GLUT-1, which is one of the key regulators of radiotherapy sensitivity. Targeted therapy directed to the PI3K/Akt pathway and GLUT-1 may disrupt the development of radiation resistance and enhance radiosensitivity, thus increasing the survival rates of cancer. Targeting GLUT-1 with antisense oligonucleotides, and the PI3K/Akt pathway with wortmannin and LY294002, in an attempt to increase radiosensitivity in laryngeal carcinoma will be the next focus for our group. The prospect of targeted therapies aimed at these molecules currently holds promise for the treatment of a variety of types of cancer.

\section{Acknowledgements}

This study was supported by the National Natural Science Foundation of China (grant nos. 81172562 and 81372903), the Science and Technology Department of Zhejiang Province, China (grant no. 2009C33026), the Health Department of Zhejiang Province (grant nos. 2010KYA062 and 2009B042) and the Department of Education of Zhejiang Province, China (grant no. Y201121184).

\section{References}

1. Jacobs SR, Herman CE, Maciver NJ, et al: Glucose uptake is limiting in $\mathrm{T}$ cell activation and requires CD28-mediated Akt-dependent and independent pathways. J Immunol 180: 4476-4486, 2008.

2. Kubicek GJ, Champ C, Fogh S, et al: FDG-PET staging and importance of lymph node SUV in head and neck cancer. Head Neck Oncol 2: 19, 2010.

3. Peng NJ, Liou WS, Liu RS, Hu C, Tsay DG and Liu CB: Early detection of recurrent ovarian cancer in patients with low-level increases in serum CA-125 levels by 2-[F-18]fluoro-2-deoxy-D -glucose-positron emission tomography/computed tomography. Cancer Biother Radiopharm 26: 175-181, 2011.

4. Masui T, Doi R, Ito T, et al: Diagnostic value of (18)F -fluorodeoxyglucose positron emission tomography for pancreatic neuroendocrine tumors with reference to the World Health Organization classification. Oncol Lett 1: 155-159, 2010.

5. Li LF, Zhou SH, Zhao K, et al: Clinical significance of FDG single-photon emission computed tomography: Computed tomography in the diagnosis of head and neck cancers and study of its mechanism. Cancer Biother Radiopharm 23: 701-714, 2008.

6. Esen Akkas B, Gökaslan D, Güner L and Ilgin Karabacak N: FDG uptake in brown adipose tissue-a brief report on brown fat with FDG uptake mechanisms and quantitative analysis using dual-time-point FDG PET/CT. Rev Esp Med Nucl 30: 14-18, 2011.

7. Ko BH, Paik JY, Jung KH and Lee KH: 17beta-estradiol augments 18F-FDG uptake and glycolysis of T47D breast cancer cells via membrane-initiated rapid PI3K-Akt activation. J Nucl Med 51: 1740-1747, 2010.

8. Prante O, Maschauer S, Fremont V, et al: Regulation of uptake of 18F-FDG by a follicular human thyroid cancer cell line with mutation-activated K-ras. J Nucl Med 50: 1364-1370, 2009.

9. Wood IS and Trayhurn P: Glucose transporters (Glut and SGLT): expanded families of sugar transport proteins. Br J Nutr 89: 3-9, 2003.

10. Sun L, Zeng X, Yan C, et al: Crystal structure of a bacterial homologue of glucose transporters GLUT1-4. Nature 490: 361-366, 2012.

11. Lastraioli E, Bencini L, Bianchini E, et al: hERG1 channels and Glut-1 as independent prognostic indicators of worse outcome in stage I and II colorectal cancer: A pilot study. Transl Oncol 5: 105-112, 2012.

12. Tong SY, Lee JM, Ki KD, et al: Correlation between FDG uptake by PET/CT and the expressions of glucose transporter type 1 and hexokinase II in cervical cancer. Int J Gynecol Cancer 22: 654-658, 2012.

13. Sasaki H, Shitara M, Yokota K, et al: Overexpression of GLUT1 correlates with Kras mutations in lung carcinomas. Mol Med Rep 5: 599-602, 2012.

14. Liu TQ, Fan J, Zhou L and Zheng SS: Effects of suppressing glucose transporter-1 by an antisense oligodeoxynucleotide on the growth of human hepatocellular carcinoma cells. Hepatobiliary Pancreat Dis Int 10: 72-77, 2011.

15. Melstrom LG, Salabat MR, Ding XZ, et al: Apigenin down-regulates the hypoxia response genes: HIF-1 $\alpha$, GLUT-1, and VEGF in human pancreatic cancer cells. J Surg Res 167: 173-181, 2011.

16. Fan J, Zhou JQ, Yu GR and Lu DD: Glucose transporter protein 1-targeted RNA interference inhibits growth and invasion of the osteosarcoma cell line MG63 in vitro. Cancer Biother Radiopharm 25: 521-527, 2010. 
17. Rademakers SE, Lok J, van der Kogel AJ, Bussink J and Kaanders JH: Metabolic markers in relation to hypoxia; staining patterns and colocalization of pimonidazole, HIF-1 $\alpha$, CAIX, LDH-5, GLUT-1, MCT1 and MCT4. BMC Cancer 11: $167,2011$.

18. Eckert AW, Lautner MH, Taubert H, Schubert J and Bilkenroth U: Expression of Glut-1 is a prognostic marker for oral squamous cell carcinoma patients. Oncol Rep 20: 1381-1385, 2008.

19. Kunkel M, Reichert TE, Benz P, et al: Overexpression of Glut-1 and increased glucose metabolism in tumors are associated with a poor prognosis in patients with oral squamous cell carcinoma. Cancer 97: 1015-1024, 2003.

20. Zhou S, Wang S, Wu Q, Fan J and Wang Q: Expression of glucose transporter-1 and -3 in the head and neck carcinoma - the correlation of the expression with the biological behaviors. ORL J Otorhinolaryngol Relat Spec 70: 189-194, 2008

21. Choi JW, Yoon DJ, Lee HW, Han DP and Ahn YH: Antisense GLUT1 RNA suppresses the transforming phenotypes of NIH $3 \mathrm{~T} 3$ cells transformed by N-Ras. Yonsei Med J 36: 480-486, 1995.

22. Chan JY, Kong SK, Choy YM, Lee CY and Fung KP: Inhibition of glucose transporter gene expression by antisense nucleic acids in HL-60 leukemia cells. Life Sci 65: 63-70, 1999.

23. Ito S, Nemoto T, Satoh S, Sekihara H, Seyama Y and Kubota S Human rhabdomyosarcoma cells retain insulin-regulated glucose transport activity through glucose transporter 1 . Arch Biochem Biophys 373: 72-82, 2000

24. Noguchi Y, Saito A, Miyagi Y, et al: Suppression of facilitative glucose transporter 1 mRNA can suppress tumor growth Cancer Lett 154: 175-182, 2000.

25. Bussink J, van der Kogel AJ and Kaanders JH: Activation of the PI3-K/AKT pathway and implications for radioresistance mechanisms in head and neck cancer. Lancet Oncol 9: 288-296, 2008.

26. Stuschke M and Thames HD: Fractionation sensitivities and dose-control relations of head and neck carcinomas: analysis of the randomized hyperfractionation trials. Radiother Oncol 51: 113-121, 1999.

27. Denekamp J, Daşu A, Waites A and Littbrand B Hyperfractionation as an effective way of overcoming radioresistance. Int J Radiat Oncol Biol Phys 42: 705-709, 1998.

28. Hingorani $M$, Colley WP, Dixit $S$ and Beavis AM: Hypofractionated radiotherapy for glioblastoma: strategy for poor-risk patients or hope for the future? Br J Radiol 85: e770-e781, 2012

29. Bollschweiler E, Hölscher AH and Metzger R: Histologic tumor type and the rate of complete response after neoadjuvant therapy for esophageal cancer. Future Oncol 6: 25-35, 2010.

30. Sho M, Akahori T, Tanaka T, et al: Pathological and clinical impact of neoadjuvant chemoradiotherapy using full-dose gemcitabine and concurrent radiation for resectable pancreatic cancer. J Hepatobiliary Pancreat Sci 20: 197-205, 2013.

31. Yamazaki H, Nakamura S, Nishimura T, et al: Hypofractionated stereotactic radiotherapy with the hypoxic sensitizer AK-2123 (sanazole) for reirradiation of brain metastases: a preliminary feasibility report. Anticancer Res 33: 1773-1776, 2013.

32. Chen FH, Chiang CS, Wang CC, et al: Vasculatures in tumors growing from preirradiated tissues: formed by vasculogenesis and resistant to radiation and antiangiogenic therapy. Int J Radiat Oncol Biol Phys 80: 1512-1521, 2011.

33. Saigusa S, Toiyama Y, Tanaka K, et al: Prognostic significance of glucose transporter-1 (GLUT1) gene expression in rectal cancer after preoperative chemoradiotherapy. Surg Today 42: 460-469, 2012.

34. Kunkel M, Moergel M, Stockinger M, et al: Overexpression of GLUT-1 is associated with resistance to radiotherapy and adverse prognosis in squamous cell carcinoma of the oral cavity. Oral Oncol 43: 796-803, 2007.

35. Doki Y, Takachi K, Ishikawa O, et al: Reduced tumor vessel density and high expression of glucose transporter 1 suggest tumor hypoxia of squamous cell carcinoma of the esophagus surviving after radiotherapy. Surgery 137: 536-544, 2005.

36. Pedersen MW, Holm S, Lund EL, Højgaard L and Kristjansen PE: Coregulation of glucose uptake and vascular endothelial growth factor (VEGF) in two small-cell lung cancer (SCLC) sublines in vivo and in vitro. Neoplasia 3: 80-87, 2001.

37. Korkeila E, Jaakkola PM, Syrjänen K, Pyrhönen S and Sundström J: Pronounced tumour regression after radiotherapy is associated with negative/weak glucose transporter-1 expression in rectal cancer. Anticancer Res 31: 311-315, 2011.
38. Korkeila EA, Sundström J, Pyrhönen S and Syrjänen K: Carbonic anhydrase IX, hypoxia-inducible factor- $1 \alpha$, ezrin and glucose transporter-1 as predictors of disease outcome in rectal cancer: multivariate Cox survival models following data reduction by principal component analysis of the clinicopathological predctors. Anticancer Res 31: 4529-4535, 2011.

39. Luo XM, Zhou SH and Fan J: Glucose transporter-1 as a new therapeutic target in laryngeal carcinoma. J Int Med Res 38 $1885-1892,2010$

40. Bai J, Guo XG and Bai XP: Epidermal growth factor receptor-related DNA repair and radiation-resistance regulatory mechanisms: a mini-review. Asian Pac J Cancer Prev 13: 4879-4881, 2012

41. Theys J, Yahyanejad S, Habets R, et al: High NOTCH activity induces radiation resistance in non small cell lung cancer. Radiother Oncol 108: 440-445, 2013.

42. Yun J, Rago C, Cheong I, et al: Glucose deprivation contributes to the development of KRAS pathway mutations in tumor cells. Science 325: 1555-1559, 2009.

43. Yasuda M, Miyazawa M, Fujita M, et al: Expression of hypoxia inducible factor-1alpha (HIF-1alpha) and glucose transporter-1 (GLUT-1) in ovarian adenocarcinomas: difference in hypoxic status depending on histological character. Oncol Rep 19 111-116, 2008.

44. Mayer A, Höckel M, Wree A and Vaupel P: Microregional expression of glucose transporter-1 and oxygenation status: lack of correlation in locally advanced cervical cancers. Clin Cancer Res 11: 2768-2773, 2005.

45. Ding XZ, Fehsenfeld DM, Murphy LO, Permert J and Adrian TE: Physiological concentrations of insulin augment pancreatic cancer cell proliferation and glucose utilization by activating MAP kinase, PI3 kinase and enhancing GLUT-1 expression. Pancreas 21: 310-320, 2000.

46. Sommermann TG, O'Neill K, Plas DR and Cahir-McFarland E: IKK $\beta$ and $N F-\kappa B$ transcription govern lymphoma cell survival through AKT-induced plasma membrane trafficking of GLUT1. Cancer Res 71: 7291-7300, 2011.

47. Wofford JA, Wieman HL, Jacobs SR, Zhao Y and Rathmell JC: IL-7 promotes Glut1 trafficking and glucose uptake via STAT5-mediated activation of Akt to support T-cell survival. Blood 111: 2101-2111, 2008.

48. Wieman HL, Wofford JA and Rathmell JC: Cytokine stimulation promotes glucose uptake via phosphatidylinositol-3 kinase/Akt regulation of Glut 1 activity and trafficking. Mol Biol Cell 18 1437-1446, 2007

49. Melstrom LG, Salabat MR, Ding XZ, et al: Apigenin inhibits the GLUT-1 glucose transporter and the phosphoinositide 3-Kinase/Akt pathway in human pancreatic cancer cells. Pancreas 37: 426-431, 2008.

50. Schuurbiers OC, Kaanders JH, van der Heijden HF, Dekhuijzen RP, Oyen WJ and Bussink J: The PI3-K/AKT-pathway and radiation resistance mechanisms in non-small cell lung cancer. J Thorac Oncol 4: 761-767, 2009.

51. Söderlund K, Pérez-Tenorio G and Stål O: Activation of the phosphatidylinositol 3-kinase/Akt pathway prevents radiation-induced apoptosis in breast cancer cells. Int $\mathbf{J}$ Oncol 26: 25-32, 2005.

52. Florczak U, Toulany M, Kehlbach R and Peter Rodemann $\mathrm{H}$ : 2-Methoxyestradiol-induced radiosensitization is independent of SOD but depends on inhibition of Akt and DNA-PKcs activities. Radiother Oncol 92: 334-338, 2009.

53. Brophy S, Sheehan KM, McNamara DA, Deasy J, Bouchier-Hayes DJ and Kay EW: GLUT-1 expression and response to chemoradiotherapy in rectal cancer. Int J Cancer 125: 2778-2782, 2009

54. Zhou SH, Fan J, Chen XM, Cheng KJ and Wang SQ: Inhibition of cell proliferation and glucose uptake in human laryngeal carcinoma cells by antisense oligonucleotides against glucose transporter-1. Head Neck 31: 1624-1633, 2009.

55. Yan SX, Luo XM, Zhou SH, et al: Effect of antisense oligodeoxynucleotides glucose transporter-1 on enhancement of radiosensitivity of laryngeal carcinoma. Int J Med Sci 10: 1375-1386, 2013

56. Upadhyay $M$, Samal J, Kandpal M, Singh OV and Vivekanandan P: The Warburg effect: insights from the past decade. Pharmacol Ther 137: 318-330, 2013.

57. Bensinger SJ, Christofk HR. New aspects of the Warburg effect in cancer cell biology. Semin Cell Dev Biol 23: 352-361, 2012.

58. Hirschhaeuser F, Sattler UG and Mueller-Klieser W: Lactate: a metabolic key player in cancer. Cancer Res 71: 6921-6925, 2011. 
59. Krzeslak A, Wojcik-Krowiranda K, Forma E, et al: Expression of GLUT1 and GLUT3 glucose transporters in endometrial and breast cancers. Pathol Oncol Res 18: 721-728, 2012.

60. Sheehan JP, Shaffrey ME, Gupta B, Larner J, Rich JN and Park DM: Improving the radiosensitivity of radioresistant and hypoxic glioblastoma. Future Oncol 6: 1591-1601, 2010.

61. Overgaard J: Hypoxic modification of radiotherapy in squamous cell carcinoma of the head and neck - a systematic review and meta-analysis. Radiother Oncol 100: 22-32, 2011.

62. Shimanishi M, Ogi K, Sogabe Y, et al: Silencing of GLUT-1 inhibits sensitization of oral cancer cells to cisplatin during hypoxia. J Oral Pathol Med 42: 382-388, 2013.

63. Pez F, Dayan F, Durivault J, et al: The HIF-1-inducible lysyl oxidase activates HIF-1 via the Akt pathway in a positive regulation loop and synergizes with HIF-1 in promoting tumor cell growth. Cancer Res 71: 1647-1657, 2011.

64. Yasuda M, Miyazawa M, Fujita M, et al: Expression of hypoxia inducible factor-1alpha (HIF-1alpha) and glucose transporter-1 (GLUT-1) in ovarian adenocarcinomas: difference in hypoxic status depending on histological character. Oncol Rep 19: 111-116, 2008.

65. Wu XH, Chen SP, Mao JY, Ji XX, Yao HT and Zhou SH: Expression and significance of hypoxia-inducible factor- $1 \alpha$ and glucose transporter-1 in laryngeal carcinoma. Oncol Lett 5: 261-266, 2013.

66. Evans A, Bates V, Troy H, et al: Glut-1 as a therapeutic target: increased chemoresistance and HIF-1-independent link with cell turnover is revealed through COMPARE analysis and metabolomic studies. Cancer Chemother Pharmacol 61: 377-393, 2008.

67. Ke CC, Liu RS, Yang AH, et al: CD133-expressing thyroid cancer cells are undifferentiated, radioresistant and survive radioiodide therapy. Eur J Nucl Med Mol Imaging 40: 61-71, 2013.

68. Piao LS, Hur W, Kim TK, et al: CD133+ liver cancer stem cells modulate radioresistance in human hepatocellular carcinoma. Cancer Lett 315: 129-137, 2012.

69. Mai HM, Zheng JW, Wang YA, et al: CD133 selected stem cells from proliferating infantile hemangioma and establishment of an in vivo mice model of hemangioma. Chin Med J (Engl) 126: 88-94, 2013.

70. Chen XH, Bao YY, Zhou SH, Wang QY, Wei Y and Fan J: Glucose transporter-1 expression in $\mathrm{CD} 133^{+}$laryngeal carcinoma Hep-2 cells. Mol Med Rep 8: 1695-1700, 2013.

71. Stein I, Neeman M, Shweiki D, Itin A and Keshet E: Stabilization of vascular endothelial growth factor mRNA by hypoxia and hypoglycemia and coregulation with other ischemia-induced genes. Mol Cell Biol 15: 5363-5368, 1995.

72. Gogineni VR, Nalla AK, Gupta R, Dinh DH, Klopfenstein JD and Rao JS: Chk2-mediated G2/M cell cycle arrest maintains radiation resistance in malignant meningioma cells. Cancer Lett 313: 64-75, 2011.

73. Hematulin A, Meethang S, Ingkaninan K and Sagan D: Derris scandens Benth extract potentiates radioresistance of Hep-2 laryngeal cancer cells. Asian Pac J Cancer Prev 13: 1289-1295, 2012.

74. Young EF, Smilenov LB, Lieberman HB and Hall EJ: Combined haploinsufficiency and genetic control of the G2/M checkpoint in irradiated cells. Radiat Res 177: 743-750, 2012.

75. Zhou Q, Lui VW and Yeo W: Targeting the PI3K/Akt/mTOR pathway in hepatocellular carcinoma. Future Oncol 7: 1149-1167, 2011.

76. Keck S, Glencer AC and Rugo HS: Everolimus and its role in hormone-resistant and trastuzumab-resistant metastatic breast cancer. Future Oncol 8: 1383-1396, 2012.

77. Webster L, Hodgkiss RJ and Wilson GD: Cell cycle distribution of hypoxia and progression of hypoxic tumour cells in vivo. Br J Cancer 77: 227-234, 1998

78. Koritzinsky M, Wouters BG, Amellem O and Pettersen EO: Cell cycle progression and radiation survival following prolonged hypoxia and re-oxygenation. Int J Radiat Biol 77: 319-328, 2001.

79. Kumareswaran R, Ludkovski O, Meng A, Sykes J, Pintilie M and Bristow RG: Chronic hypoxia compromises repair of DNA double-strand breaks to drive genetic instability. J Cell Sci 125 189-199, 2012.

80. Toustrup K, Sørensen BS, Nordsmark M, et al: Development of a hypoxia gene expression classifier with predictive impact for hypoxic modification of radiotherapy in head and neck cancer. Cancer Res 71: 5923-5931, 2011.

81. Koumenis C: ER stress, hypoxia tolerance and tumor progression. Curr Mol Med 6: 55-69, 2006.
82. Kitagawa N, Kondo S, Wakisaka N, et al: Expression of seven-in-absentia homologue 1 and hypoxia-inducible factor 1 alpha: novel prognostic factors of nasopharyngeal carcinoma. Cancer Lett 331: 52-57, 2013.

83. Pentheroudakis G, Nicolaou I, Kotoula V, et al: Prognostic utility of angiogenesis and hypoxia effectors in patients with operable squamous cell cancer of the larynx. Oral Oncol 48: 709-716, 2012.

84. Moeller BJ, Cao Y, Li CY and Dewhirst MW: Radiation activates HIF-1 to regulate vascular radiosensitivity in tumors: role of reoxygenation, free radicals, and stress granules. Cancer Cell 5: 429-441, 2004.

85. Kim WY, Oh SH, Woo JK, Hong WK and Lee HY: Targeting heat shock protein 90 overrides the resistance of lung cancer cells by blocking radiation-induced stabilization of hypoxia-inducible factor-1alpha. Cancer Res 69: 1624-1632, 2009.

86. Lee SM, Lee CT, Kim YW, Han SK, Shim YS and Yoo CG: Hypoxia confers protection against apoptosis via PI3K/Akt and ERK pathways in lung cancer cells. Cancer Lett 242: 231-238, 2006.

87.Edwards E, Geng L, Tan J, Onishko H, Donnelly E and Hallahan DE: Phosphatidylinositol 3-kinase/Akt signaling in the response of vascular endothelium to ionizing radiation. Cancer Res 62: 4671-4677, 2002.

88. Kumar P, Miller AI and Polverini PJ: p38 MAPK mediates gamma-irradiation-induced endothelial cell apoptosis and vascular endothelial growth factor protects endothelial cells through phosphoinositide 3-kinase-Akt-Bcl-2 pathway. J Biol Chem 279: 43352-43360, 2004.

89. Kumar P, Benedict R, Urzua F, Fischbach C, Mooney D and Polverini P: Combination treatment significantly enhances the efficacy of antitumor therapy by preferentially targeting angiogenesis. Lab Invest 85: 756-767, 2005.

90. Wu J, Chen C and Zhao KN: Phosphatidylinositol 3-kinase signaling as a therapeutic target for cervical cancer. Curr Cancer Drug Targets 13: 143-156, 2013.

91. Shinohara ET and Maity A: Increasing sensitivity to radiotherapy and chemotherapy by using novel biological agents that alter the tumor microenvironment. Curr Mol Med 9: 1034-1045, 2009.

92. Fokas E, McKenna WG and Muschel RJ: The impact of tumor microenvironment on cancer treatment and its modulation by direct and indirect antivascular strategies. Cancer Metastasis Rev 31: 823-842, 2012.

93.Zhan M and Han ZC: Phosphatidylinositide 3-kinase/AKT in radiation responses. Histol Histopathol 19: 915-923, 2004.

94. Park JK, Jung HY, Park SH, et al: Combination of PTEN and gamma-ionizing radiation enhances cell death and $\mathrm{G}(2) / \mathrm{M}$ arrest through regulation of AKT activity and p21 induction in non-small-cell lung cancer cells. Int J Radiat Oncol Biol Phys 70: 1552-1560, 2008.

95. Kandel ES, Skeen J, Majewski N, et al: Activation of Akt/protein kinase B overcomes a G(2)/m cell cycle checkpoint induced by DNA damage. Mol Cell Biol 22: 7831-7841, 2002.

96. Mukherjee B, Tomimatsu N, Amancherla K, Camacho CV Pichamoorthy $\mathrm{N}$ and Burma S: The dual PI3K/mTOR inhibitor NVP-BEZ235 is a potent inhibitor of ATM- and DNA-PKCs-mediated DNA damage responses. Neoplasia 14: 34-43, 2012

97. Yang J, Xu X, Hao Y, et al: Expression of DNA-PKes and BRCA1 as prognostic indicators in nasopharyngeal carcinoma following intensity-modulated radiation therapy. Oncol Lett 5: 1199-1204, 2013.

98. Millet P, Granotier C, Etienne O and Boussin FD: Radiation-induced upregulation of telomerase activity escapes PI3-kinase inhibition in two malignant glioma cell lines. Int J Oncol 43: 375-382, 2013.

99. Qu YY, Hu SL, Xu XY, et al: Nimotuzumab enhances the radiosensitivity of cancer cells in vitro by inhibiting radiation-induced DNA damage repair. PLoS One 8: e70727, 2013.

100.Zhang T, Cui GB, Zhang J, et al: Inhibition of PI3 kinases enhances the sensitivity of non-small cell lung cancer cells to ionizing radiation. Oncol Rep 24: 1683-1689, 2010.

101. Azad A, Jackson S, Cullinane C, et al: Inhibition of DNA-dependent protein kinase induces accelerated senescence in irradiated human cancer cells. Mol Cancer Res 9: 1696-1707, 2011.

102. Li HF, Kim JS and Waldman T: Radiation-induced Akt activation modulates radioresistance in human glioblastoma cells. Radiat Oncol 4: 43, 2009. 
103. Minjgee M, Toulany M, Kehlbach R, Giehl K and Rodemann HP: K-RAS(V12) induces autocrine production of EGFR ligands and mediates radioresistance through EGFR-dependent Akt signaling and activation of DNA-PKcs. Int J Radiat Oncol Biol Phys 81: 1506-1514, 2011.

104.Petrás M, Lajtos T, Friedländer E, et al: Molecular interactions of ErbB1 (EGFR) and integrin- $\beta 1$ in astrocytoma frozen sections predict clinical outcome and correlate with Akt-mediated in vitro radioresistance. Neuro Oncol 15: 1027-1040, 2013.

105. Gautier EL, Westerterp M, Bhagwat N, et al: HDL and Glut1 inhibition reverse a hypermetabolic state in mouse models of myeloproliferative disorders. J Exp Med 210: 339-353, 2013.

106. Swainson L, Kinet S, Mongellaz C, Sourisseau M, Henriques T and Taylor N: IL-7-induced proliferation of recent thymic emigrants requires activation of the PI3K pathway. Blood 109 $1034-1042,2007$

107. Rathmell JC, Fox CJ, Plas DR, Hammerman PS, Cinalli RM and Thompson CB: Akt-directed glucose metabolism can prevent Bax conformation change and promote growth factor-independent survival. Mol Cell Biol 23: 7315-7328, 2003.

108.Zhao Y, Altman BJ, Coloff JL, et al: Glycogen synthase kinase 3alpha and 3 beta mediate a glucose-sensitive antiapoptotic signaling pathway to stabilize Mcl-1. Mol Cell Biol 27: 4328-4339, 2007

109. Roberts MS, Woods AJ, Dale TC, Van Der Sluijs P and Norman JC: Protein kinase B/Akt acts via glycogen synthase kinase 3 to regulate recycling of alpha v beta 3 and alpha 5 beta 1 integrins. Mol Cell Biol 24: 1505-1515, 2004.

110. Doughty CA, Bleiman BF, Wagner DJ, et al: Antigen receptor-mediated changes in glucose metabolism in B lymphocytes: role of phosphatidylinositol 3-kinase signaling in the glycolytic control of growth. Blood 107: 4458-4465, 2006.

111. Marko AJ, Miller RA, Kelman A and Frauwirth KA: Induction of glucose metabolism in stimulated T lymphocytes is regulated by mitogen-activated protein kinase signaling. PLoS One 5: e15425, 2010.

112. Radhakrishnan P, Baraneedharan U, Veluchamy S, et al: Inhibition of rapamycin-induced AKT activation elicits differential antitumor response in head and neck cancers. Cancer Res 73: 1118-1127, 2013

113. Samih N, Hovsepian S, Aouani A, Lombardo D and Fayet G: Glut-1 translocation in FRTL-5 thyroid cells: role of phosphatidylinositol 3-kinase and N-glycosylation. Endrocrinology 141: 4146-4155, 2000

114. Clarke JF, Young PW, Yonezawa K, Kasuga M and Holman GD: Inhibition of the translocation of GLUT1 and GLUT4 in 3T3-L1 cells by the phosphatidylinositol 3-kinase inhibitor, wortmannin Biochem J 300: 631-635, 1994.

115. Golkar L, Salabat MR, Ding XZ, et al: Apigenin inhibits pancreatic cancer cell proliferation via down-regulation of the GLUT-1 glucose transporter through the phosphoinositide 3-kinase (PI3K)/Akt signaling pathway (Abstract). Pancreas 33: 464, 2006.

116. Pore N, Jiang Z, Shu HK, Bernhard E, Kao GD and Maity A: Akt1 activation can augment hypoxia-inducible factor-1alpha expression by increasing protein translation through a mammalian target of rapamycin-independent pathway. Mol Cancer Res 4: 471-479, 2006.

117. Plas DR, Talapatra S, Edinger AL, Rathmell JC and Thompson CB: Akt and Bcl-xL promote growth factor-independent survival through distinct effects on mitochondrial physiology. J Biol Chem 276: 12041-12048, 2001.
118. Fang J, Bao YY, Zhou SH, et al. Recurrent prognostic factors and expression of GLUT-1, PI3K and p-Akt in adenoid cystic carcinomas of the head and neck: Clinicopathological features and biomarkers of adenoid cystic carcinoma. Oncol Lett 4 : 1234-1240, 2012.

119. Shen WQ, Cheng KJ, Bao YY, Zhou SH and Yao HT: Expression of Glut-1, HIF-1 $\alpha$, PI3K and p-Akt in a case of ceruminous adenoma. Head Neck Oncol 4: 18, 2012.

120. Silva A, Gírio A, Cebola I, Santos CI, Antunes F and Barata JT: Intracellular reactive oxygen species are essential for $\mathrm{PI} 3 \mathrm{~K} / \mathrm{Akt} / \mathrm{mTOR}$-dependent IL-7-mediated viability of T-cell acute lymphoblastic leukemia cells. Leukemia 25: 960-967, 2011

121. Barata JT, Silva A, Brandao JG, Nadler LM, Cardoso AA and Boussiotis VA: Activation of PI3K is indispensable for interleukin 7-mediated viability, proliferation, glucose use, and growth of $\mathrm{T}$ cell acute lymphoblastic leukemia cells. J Exp Med 200: 659-669, 2004

122. Wahl H, Daudi S, Kshirsagar M, et al: Expression of metabolically targeted biomarkers in endometrial carcinoma. Gynecol Oncol 116: 21-27, 2010.

123. Fumarola C,Caffarra C,La Monica S, et al: Effects of sorafenib on energy metabolism in breast cancer cells: role of AMPK-mTORC1 signaling. Breast Cancer Res Treat 141: 67-78, 2013.

124. Ou J, Luan W, Deng J, Sa R and Liang H: $\alpha \mathrm{V}$ integrin induces multicellular radioresistance in human nasopharyngeal carcinoma via activating SAPK/JNK pathway. Plos One 7: e38737, 2012.

125.Xiao H, Zhang Q, Shen J, Bindokas V and Xing HR Pharmacologic inactivation of kinase suppressor of Ras1 sensitizes epidermal growth factor receptor and oncogenic Ras-dependent tumors to ionizing radiation treatment. Mol Cancer Ther 9: 2724-2736, 2010.

126. Li P, Zhang Q, Torossian A, et al: Simultaneous inhibition of EGFR and PI3K enhances radiosensitivity in human breast cancer. Int J Radiat Oncol Biol Phys 83: e391-e397, 2012.

127. Tan C, de Noronha RG, Roecker AJ, et al: Identification of a novel small-molecule inhibitor of the hypoxia-inducible factor 1 pathway. Cancer Res 65: 605-612, 2005.

128. Romeo Y and Roux PP: Paving the way for targeting RSK in cancer. Expert Opin Ther Targets 15: 5-9, 2011.

129. Cataldi A, di Giacomo V, Rapino M, Genovesi D and Rana RA: Cyclic nucleotide Response Element Binding protein (CREB) activation promotes survival signal in human K562 erythroleukemia cells exposed to ionising radiation/etoposide combined treatment. J Radiat Res 47: 113-120, 2006.

130. Moretti L, Yang ES, Kim KW and Lu B: Autophagy signaling in cancer and its potential as novel target to improve anticancer therapy. Drug Resist Updat 10: 135-143, 2007.

131. Shinohara ET, Cao C, Niermann K, et al: Enhanced radiation damage of tumor vasculature by mTOR inhibitors. Oncogene 24: 5414-5422, 2005.

132. Hudes G, Carducci M, Tomczak P, et al: Temsirolimus, interferon alpha, or both for advanced renal-cell carcinoma. N Engl J Med 356: 2271-2281, 2007. 